\title{
Distinct Sites of Opiate Reward and Aversion within the Midbrain Identified Using a Herpes Simplex Virus Vector Expressing GluR1
}

\author{
William A. Carlezon Jr, ${ }^{1}$ Colin N. Haile, ${ }^{1}$ Robert Coopersmith, ${ }^{2}$ Yasunori Hayashi, ${ }^{3}$ Roberto Malinow, ${ }^{3}$ \\ Rachael L. Neve, ${ }^{2}$ and Eric J. Nestler ${ }^{1}$ \\ ${ }^{1}$ Division of Molecular Psychiatry, Center for Genes and Behavior, Yale University School of Medicine and Connecticut \\ Mental Health Center, New Haven, Connecticut 06508, ²Department of Genetics, Harvard Medical School, McLean \\ Hospital, Belmont Massachusetts 02478, and ${ }^{3}$ Cold Spring Harbor Laboratory, Cold Spring Harbor, New York 11724
}

Repeated administration of morphine increases expression of GluR1 (an AMPA glutamate receptor subunit) in the ventral tegmental area (VTA) of the midbrain, an important neural substrate for the rewarding actions of morphine. Microinjections of a herpes simplex virus (HSV) vector that causes local overexpression of GluR1 (HSV-GluR1) into the VTA can enhance the ability of morphine to establish conditioned place preferences, suggesting that altered GluR1 expression in this region is directly associated with changes in the rewarding efficacy of morphine. We now report that in rats given HSV-GluR1 directly into the VTA, morphine is most rewarding when maximal transgene expression is in the rostral VTA, whereas morphine is aversive when maximal transgene expression is in the caudal VTA. Dual-labeling immunohistochemistry shows that this difference cannot be explained by a different fraction of dopaminergic neurons infected in the rostral versus caudal VTA. No such anatomical specificity is seen in rats given VTA microinjections of HSV-LacZ, a vector expressing a control protein $(\beta$-galactosidase). These results suggest that distinct substrates within the VTA itself differentially contribute to the rewarding and aversive properties of opiates.

Key words: morphine; reward; place conditioning; glutamate; AMPA; viral vector
The ventral tegmental area (VTA) of the midbrain contains the cell bodies of the mesolimbic dopamine (DA) system, a major neural substrate for many drugs of abuse (Koob and Nestler, 1997; Wise, 1998). The reward-related effects of systemic opiates (Weeks and Collins, 1964; Rossi and Reid, 1976; Carlezon and Wise, 1993) involve opioid receptors in the VTA: injections of morphine directly into the VTA potentiate the rewarding impact of hypothalamic brain stimulation (Broekkamp et al., 1976), establish conditioned place preferences (Bozarth, 1987), and reinforce lever pressing (Bozarth and Wise, 1981). Additionally, VTA injections of morphine reinstate extinguished responding in rats trained to lever press for intravenous heroin (Stewart, 1984). Opiates have their most potent reward-related effects in the VTA (see Wise, 1998), although they also have rewarding actions in other brain regions such as the nucleus accumbens (NAcc) (Olds, 1982; see Koob and Nestler, 1997).

The rewarding properties of opiates in the VTA are likely associated with their ability to promote DA release, particularly from cells that project to the NAcc (e.g., Leone et al., 1991). Opiates produce this effect by reducing tonic inhibition of the dopaminergic neurons through actions at $\mu$ and $\delta$ receptors on GABAergic interneurons (Gysling and Wang, 1983; Johnson and North, 1992). However, there is recent evidence that the excita-

\footnotetext{
Received Sept. 23, 1999; revised Dec. 22, 1999; accepted Dec. 28, 1999.

This work was supported by Grants DA08227, DA07359 (E.J.N.), and DA05758 (W.A.C.) from the National Institute on Drug Abuse, Grant MH49159 (R.M.) from the National Institute of Mental Health, and Grant HD34563 (R.L.N.) from the National Institute on Child Health and Human Development. We thank V. G. Olson for contributions.

Correspondence should be addressed to Dr. William A. Carlezon Jr, Department of Psychiatry, McLean Hospital, MRC 217, 115 Mill Street, Belmont MA 02478. E-mail: carlezon@mclean.harvard.edu.

Copyright (C) 2000 Society for Neuroscience $\quad 0270-6474 / 00 / 200001-06 \$ 15.00 / 0$
}

tory effects of glutamate at AMPA receptors located on VTA dopaminergic neurons are also involved in the actions of drugs of abuse, with increased AMPA receptor function seen after chronic drug exposure (Zhang et al., 1997). Furthermore, repeated intermittent drug exposure upregulates expression of the AMPA receptor subunit GluR1 in the VTA (Fitzgerald et al., 1996), and selective overexpression of GluR1 in the rostral VTA by viral-mediated gene transfer can enhance the rewarding effects of morphine (Carlezon et al., 1997). These results suggest that drug exposure causes increased formation of $\mathrm{Ca}^{2+}$-permeable AMPA receptors and subsequent increased sensitivity of dopaminergic neurons to the excitatory effects of glutamate.

One advantage of viral-mediated gene transfer is that the location of neurons that overexpress the transgene (e.g., GluR1) can be precisely determined using immunohistochemical analyses. This anatomical specificity allows a more precise analysis of the neural substrate of opiate actions within the VTA compared with studies in which conclusions are based on the location of a microinjection site from which opiates diffuse. Through the use of viral-mediated transfer of GluR1 into the VTA, we now report

This article is published in The Journal of Neuroscience, Rapid Communications Section, which publishes brief, peerreviewed papers online, not in print. Rapid Communications are posted online approximately one month earlier than they would appear if printed. They are listed in the Table of Contents of the next open issue of JNeurosci. Cite this article as: JNeurosci, 2000, 220:RC62 (1-5). The publication date is the date of posting online at www.jneurosci.org.

http://www.jneurosci.org/cgi/content/full/3983 
that there is a topographical organization of opiate rewardrelevant sites within the VTA itself, similar to that reported by Bozarth (1987). Using place conditioning, we have determined that GluR1 overexpression in rostral VTA dramatically increases the rewarding effects of a low (threshold) dose of systemic morphine, whereas GluR1 overexpression in caudal VTA makes the same morphine treatment aversive.

\section{MATERIALS AND METHODS}

A total of 110 male Sprague Dawley rats (325-375 gm) were used; 106 were used for the place-conditioning studies, and 4 were used for duallabeling studies to determine the identities of neurons expressing the viral transgenes. Place conditioning occurred in a three-compartment apparatus, as described (Carlezon et al., 1997). On the screening day (day $0)$ rats were placed in the small $(12 \times 18 \times 33 \mathrm{~cm})$ central compartment and were allowed to explore the entire apparatus for $30 \mathrm{~min}$; compartments differed in floor texture, wall striping, and lighting. Rats that did not show a baseline preference $(\geq 18 \mathrm{~min})$ for a compartment were anesthetized $(65 \mathrm{mg} / \mathrm{kg}$ sodium pentobarbital, i.p.) and received unilateral VTA microinjections $(2.0 \mu \mathrm{l}$ over $10 \mathrm{~min})$ of either herpes simplex virus (HSV)-GluR1 (expressing GluR1; $n=49$ ) or HSV-LacZ (expressing $\beta$-galactosidase, a control protein; $n=39)$ or sham surgery $(n=18)$. For the place-conditioning studies, anteroposterior (AP) coordinates (Paxinos and Watson, 1986) ranged from 4.2 to $6.4 \mathrm{~mm}$ posterior to bregma, with lateral $= \pm 2.0$ and dorsoventral $=7.6 \mathrm{~mm}$ below dura; the injection syringe was angled at $10^{\circ}$ from the midline. For sham surgery, the injection needle (26 gauge) was lowered $1.0 \mathrm{~mm}$ below dura, but no injections were made. For dual-labeling studies, injections of HSVGluR1-GFP [expressing a GluR1-green fluorescent protein (GFP) fusion protein; Shi et al., 1999] were aimed at the middle of the VTA (AP, $-5.3 \mathrm{~mm}$ posterior to bregma).

Conditioning trials (two per day) were given on 2 consecutive days (days 3 and 4). On the first conditioning trial of each day, rats received saline $(1 \mathrm{ml} / \mathrm{kg}$, s.c. $)$ and were confined to one of the large $(24 \times 18 \times 33$ $\mathrm{cm}$ ) side compartments of the apparatus for $1 \mathrm{hr} ; 3 \mathrm{hr}$ later, rats received morphine $(0.5 \mathrm{mg} / \mathrm{kg}$, s.c. $)$ and were confined to the other side compartment for $1 \mathrm{hr}$. On the following day (day 5), rats were again allowed to freely explore the entire apparatus for $30 \mathrm{~min}$. Place-conditioning data were analyzed using a one-way ANOVA, followed by post hoc comparisons with Dunnett's $t$ tests (two-tailed) using sham-treated rats as controls.

Construction of the viral vectors has been described elsewhere (Neve et al., 1997). For place-conditioning studies, GluR1 or LacZ cDNAs were inserted into the HSVPrpUC amplicon, packaged with helper 5dl1.2, purified on a sucrose gradient, pelleted, and resuspended in $10 \%$ sucrose. For dual-labeling studies, cDNA for GluR1-GFP was inserted into the amplicon. Average titer of the viral stocks was $2.0 \times 10^{7}$ infectious units/ml; transgene expression was regulated by HSV IE $4 / 5$.

After testing (or $3 \mathrm{~d}$ after microinjections of HSV-GluR1-GFP), rats were overdosed with pentobarbital and perfused with $0.9 \%$ saline followed by $4 \%$ paraformaldehyde. Brains were post fixed for $24 \mathrm{hr}$ and kept overnight in $20 \%$ glycerol before slicing. Slices $(40 \mu \mathrm{m})$ were examined for expression of GluR1 (using anti-GluR1, 1:100; Chemicon, Temecula, $\mathrm{CA}$ ) or of $\beta$-galactosidase (using 5-bromo-4-chloro-3-indolyl- $\beta$-Dgalactopyranosidase, $0.2 \mathrm{mg} / \mathrm{ml}$; Boehringer Mannheim, Indianapolis, IN) according to described methods (Carlezon et al., 1997). For each brain, the area of maximal transgene expression was determined in every sixth slice with the assistance of an observer blinded to the behavioral data. Some slices were stained for tyrosine hydroxylase (TH; using anti-TH, 1:2000; Eugene Tech International) or analyzed by Nissl staining.

Confocal microscopy was used to determine the percentage of GluR1overexpressing neurons that were dopaminergic in the anterior and posterior portions of the VTA. Slices $(20 \mu \mathrm{m})$ were incubated simultaneously in a rabbit-derived antibody for GFP (to identify neurons overexpressing the GluR1-GFP fusion protein; Molecular Probes, Eugene OR; $1: 400$ ) and a mouse-derived antibody for TH (to identify dopaminecontaining neurons: Chemicon; 1:800). Using a confocal microscope (TCS NT; Leica, Nussloch, Germany), GFP immunoreactivity was visualized with FITC-conjugated goat anti-rabbit IgG (Cappel, West Chester, PA; 1:200), and TH immunoreactivity was visualized with rhodamine-conjugated goat anti-mouse IgG (Cappel; 1:200). Laser excitation wavelengths and filters specific for visualizing FITC and rhoda- mine were used. The total number of GFP-labeled cells throughout the rostral-caudal extent of the VTA was determined in every sixth brain slice, and the percentage of those cells that co-expressed TH was calculated. Between-region differences were analyzed using an $F$ test.

\section{RESULTS}

TH immunoreactivity in the portion of the midbrain comprising the VTA (Paxinos and Watson, 1986) was found along an $\sim 1.8$ $\mathrm{mm}$ rostral-caudal axis, corresponding to $\sim 4.4-6.2 \mathrm{~mm}$ posterior to bregma. In the rostral portions of the VTA (Fig. 1A), TH-positive cell bodies were most apparent medially, dorsal to the mammilary peduncle; this area of the VTA, together with immediately adjacent regions such as the supramamillary nucleus, is known to contain significant numbers of TH-containing neurons from the A10 (mesolimbic) cell group (Dahlstrom and Fuxe, 1964; Swanson, 1982). In the caudal portions of the VTA (Fig. $1 D)$, TH-positive cell bodies were apparent medially and laterally, to the point of the delineation of the substantia nigra compacta. As reported previously (Carlezon et al., 1997), microinjections of HSV-LacZ or HSV-GluR1 into the VTA results in 1000-2000 transgene-labeled cells 3 d after viral vector treatment (when place conditioning and drug pairing was initiated); however, when the rats in the present study were killed after testing, $5 \mathrm{~d}$ after gene transfer, these numbers were typically lower (see Fig. 1B,E,F), because of the transient nature of transgene expression (Carlezon et al., 1997; Neve et al., 1997). There were no apparent differences in the total number of infected neurons between rostral versus caudal VTA injection placements. HSV vectors caused minimal damage (Fig. 1C; Carlezon et al., 1997) that was indistinguishable from that caused by injection of vehicle (10\% sucrose).

The effects of morphine $(0.5 \mathrm{mg} / \mathrm{kg}$, s.c. $)$ on place conditioning (Fig. 2$)$ depended on the type of treatment at surgery $\left(F_{(8,98)}=\right.$ 3.33; $p<0.01)$. The effects of morphine in rats given HSV-LacZ did not differ at any coordinate from those in rats that received sham surgery (controls). However, the effects of morphine in rats given HSV-GluR1 differed profoundly according to placement: rats spent significantly more time in morphine-associated environments than controls when viral-mediated overexpression of GluR1 was maximal in the rostral VTA [corresponding to 4.4-5.3 $\mathrm{mm}$ posterior to bregma, rostral to the level of the interpeduncular nucleus (IPN)], whereas rats spent significantly less time in morphine-associated environments than controls when GluR1 overexpression was maximal in the caudal VTA (corresponding to 5.3-6.2 mm posterior to bregma, at, and caudal to, the level of the IPN). Microinjections of HSV-GluR1 outside of the VTA $(<4.4$ or $>6.2 \mathrm{~mm}$ posterior to bregma) had no effect on morphine place conditioning.

Confocal microscopy (Fig. 3) revealed that $59 \%$ of the cells overexpressing the GluR1-GFP fusion protein in the rostral VTA were TH-positive (i.e., dopaminergic), whereas $71 \%$ of the GluR1GFP-positive cells in the caudal VTA were dual-labeled. This difference was not statistically significant $\left(F_{(12,37)}=1.16\right.$; NS).

\section{DISCUSSION}

Viral-mediated overexpression of GluR1 in the rostral VTA dramatically enhances the rewarding effects of a threshold dose of morphine $(0.5 \mathrm{mg} / \mathrm{kg}$, s.c. $)$, whereas GluR1 overexpression in the caudal VTA makes the same dose of the drug aversive. Overexpression of GluR1 results in increased formation of $\mathrm{Ca}^{2+}$ permeable (GluR1-homomeric) AMPA receptors (Carlezon et al., 1997; Neve et al., 1997), which presumably causes increases in sensitivity to the excitatory (depolarizing) effects of glutamate in 


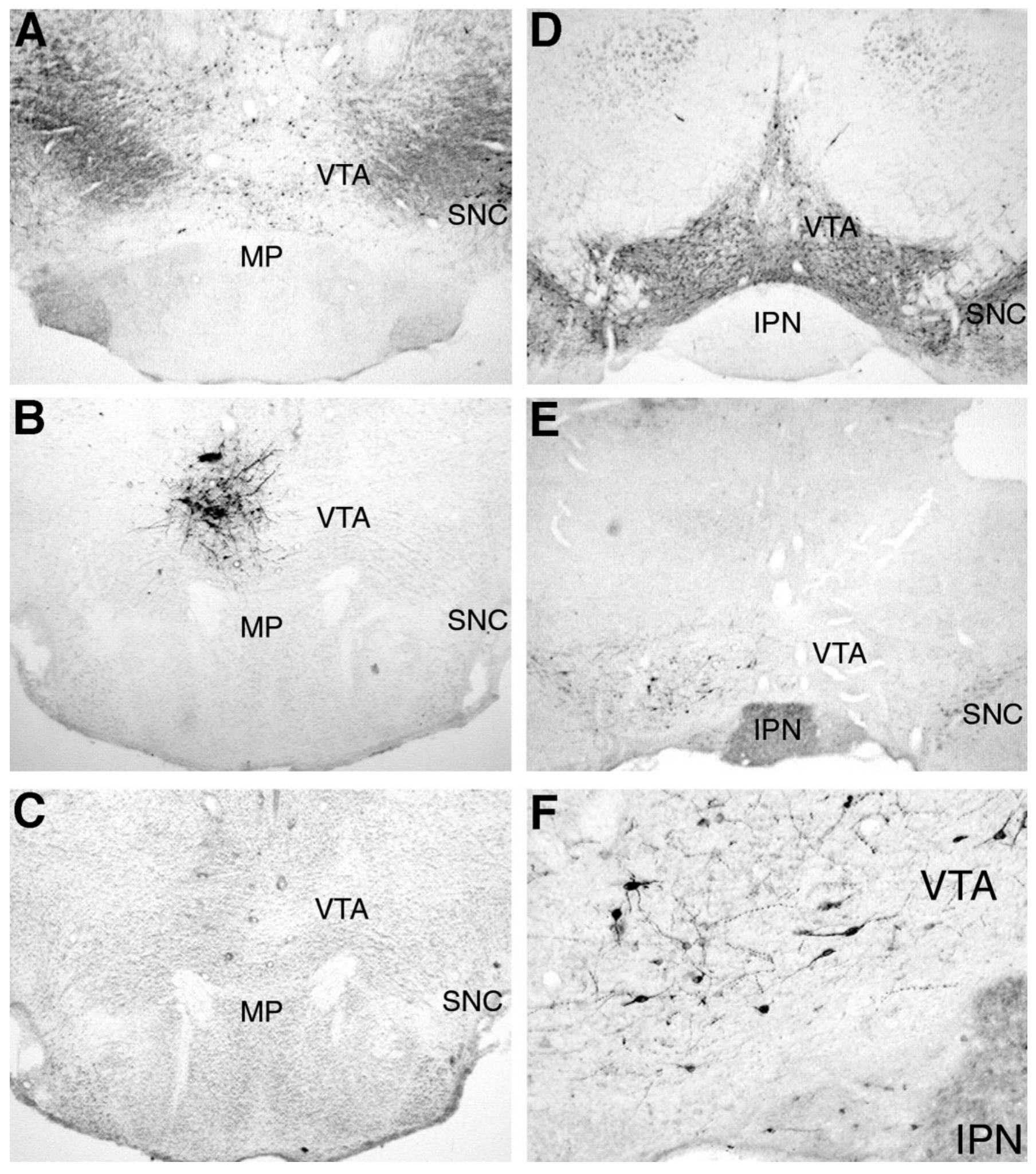

Figure 1. Histological examination of the VTA. A, Expression of TH in the rostral VTA $(\sim 4.8 \mathrm{~mm}$ posterior to bregma). Large numbers of darkly stained, TH-positive neurons are located medially at this level of the VTA (magnification, $25 \times$ ). B, Expression of $\beta$-galactosidase $5 \mathrm{~d}$ after injection of HSV-LacZ into the left VTA. Morphine reward was enhanced by microinjections of HSV-GluR1 into this portion of the VTA but not by similar treatment with HSV-LacZ. $C$, Adjacent, Nissl-stained section from the same brain as in $B$, showing lack of gliosis in the region of transgene expression. $D$, Expression of TH in the caudal VTA $(\sim 5.8 \mathrm{~mm}$ posterior to bregma). Darkly stained, TH-positive neurons are distributed medially and laterally at this level of the VTA. In addition to cell bodies, neuropil is also stained darkly at this level. E, Expression of GluR1 $5 \mathrm{~d}$ after injection of HSV-GluR1 into the left VTA. Morphine was made aversive by microinjections of HSV-GluR1 into this region of the VTA but not by similar treatment with HSV-LacZ. Note the endogenous GluR1 immunoreactivity in the IPN, the primary anatomical landmark used for determining rostral or caudal placements. $F$, Higher magnification $(100 \times)$ of the slice in $(E)$. MP, Mammilary peduncle; $S N C$, substantia nigra compacta. 


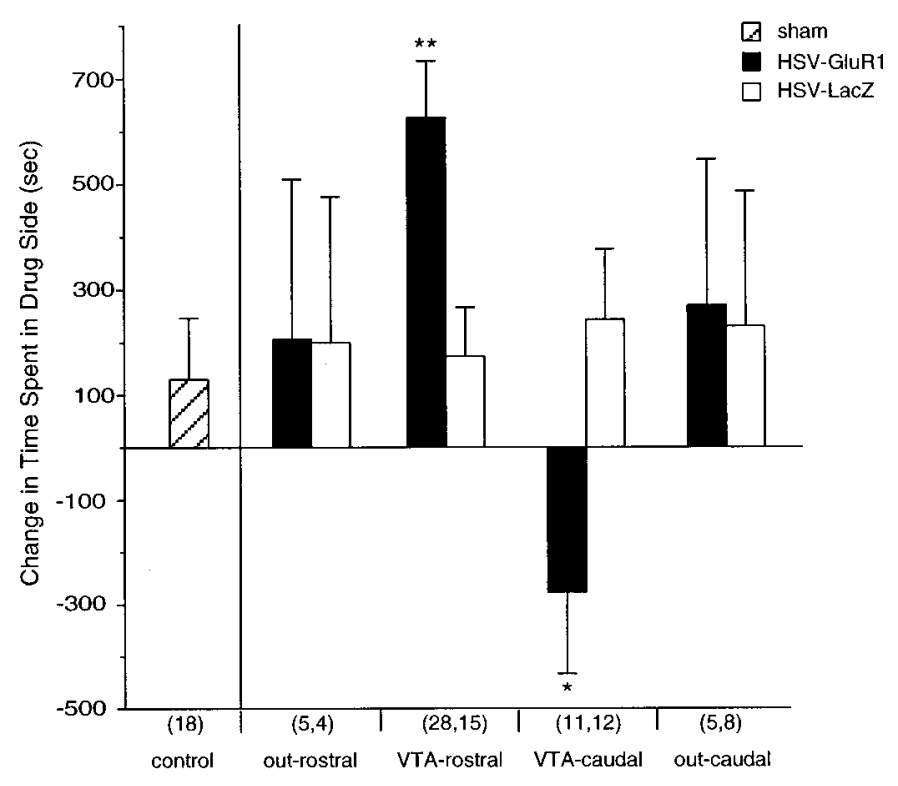

Figure 2. Effect of a threshold dose of morphine $(0.5 \mathrm{mg} / \mathrm{kg}$, s.c., for $2 \mathrm{~d})$ on place conditioning in rats given HSV-GluR1 or HSV-LacZ into the VTA. Control rats received sham surgery. Place-conditioning data are presented as mean \pm SEM change (before minus after) in time (seconds) spent in the morphine-associated environment. Rats given HSV-GluR1 into the rostral VTA spent significantly more time in morphine-associated environments than controls (sham), whereas those given HSV-GluR1 into the caudal VTA spent less time in morphine-associated environments. HSV-GluR1 had no consequence on morphine place conditioning when placements were made anterior (out-rostral) or posterior (out-caudal) to the VTA; likewise, HSV-LacZ had no effect at any coordinate. * $p<0.05$; $*^{*} p<0.01$ (Dunnett's $t$ test) compared with sham control for each placement; numbers in parentheses indicate the number of rats given each treatment (e.g., HSV-GluR1 or HSV-LacZ).

the dopaminergic neuron-rich VTA. These studies using viralmediated gene transfer and systemic drug administration support previous studies using intracranial drug administration that suggest topographical differences in the reward-relevant properties of drugs within the VTA (Bozarth, 1987; Ikemoto et al., 1997b). Moreover, because the immunohistochemical analyses used in the present studies allow precise anatomical localization of neurons affected by gene transfer, for the first time portions of the VTA have been identified within which opiates may have aversive actions.

There are several possible explanations for these results. First, it is possible that different populations of neurons mediate the effects of GluR1 overexpression in the rostral VTA than in the caudal VTA. Both the rostral and caudal VTA contain large numbers of $\mathrm{TH}$-positive cell bodies, although more neuropil $\mathrm{TH}$ staining is evident in the caudal VTA (Fig. 1, compare $A, D$ ). Dual-labeling immunohistochemistry studies show that the majority of cells induced virally to overexpress GluR1 were THpositive (i.e., dopaminergic) in both the anterior and posterior VTA, although the percentage was slightly (12\%) lower in the anterior VTA. Because the HSV vectors used are not selective for any particular type of neuron, the behavioral effect observed would be expected to reflect increased sensitivity of the predominant type of neuron to the excitatory effects of glutamate. Based on independent observations, increased excitability of GABAergic interneurons (the other predominant neuronal type within the VTA) in either the rostral or caudal VTA is unlikely to cause the pattern of behavioral effects seen in the present study. Rats self-administer the $\mathrm{GABA}_{\mathrm{A}}$ antagonist picrotoxin directly into the anterior VTA (Ikemoto et al., 1997b), where viral-mediated GluR1 overexpression caused morphine place preferences. Blockade of $\mathrm{GABA}_{\mathrm{A}}$ receptors in the anterior VTA causes marked increases in extracellular concentrations of DA in the NAcc (Ikemoto et al., 1997a), an effect presumably caused by decreases in GABA-mediated inhibition of midbrain dopaminergic neurons. Thus, decreases in GABA inhibition caused by picrotoxin in the anterior VTA likely have consequences similar to increases in the excitability of dopaminergic neurons caused by viral-mediated overexpression of GluR1-homomeric receptors. Conversely, rats do not self-administer picrotoxin into the posterior VTA (Ikemoto et al., 1997b), where overexpression of GluR1 caused morphine place aversions. These previous studies provide further support for the notion that there is significant heterogeneity of drug actions between the rostral and caudal VTA, similar to that identified for morphine in the present studies.

A second possibility is that dopaminergic neurons in the rostral VTA might have fundamentally different characteristics from those in the caudal VTA. There is evidence from retrograde labeling studies that the forebrain projection patterns of dopaminergic cells in the caudal VTA differ substantially from those in the rostral VTA: caudal VTA sites appear to project predominantly to the prefrontal cortex (PFC) and NAcc shell, whereas rostral sites appear to project predominately to the NAcc shell and core (Brog et al., 1993). However, the relevance of this difference in projection patterns for opiate reward is unknown; although both the PFC and NAcc shell (but not the NAcc core) appear to contribute to stimulant reward (see Carlezon and Wise, 1996), the precise substrates of opiate reward within the NAcc have not been identified. Earlier studies that do not distinguish between the NAcc core and shell suggest that GABAergic projection neurons of the NAcc differentially innervate the anterior and posterior VTA (Walaas and Fonnum, 1980), with a more substantial innervation of regions in which viral-mediated overexpression of GluR1 increased morphine reward. Also, differential projections from these VTA subregions to brain regions other than the PFC and NAcc may contribute to the behavioral effects observed. For example, the rostral but not caudal VTA sends direct descending projections to the laterodorsal tegmental nucleus (Cornwall et al., 1990). This region, together with the adjacent and neurochemically related pedunculopontine nucleus, are pontine nuclei that have been implicated in opiate reward (Olmstead et al., 1998). The consequences of differentially changing the sensitivity of these neuronal circuits to the excitatory effects of glutamate by overexpression of GluR1 in the VTA are not known but could be addressed in future studies by using electrical stimulation delivered through electrodes placed in either the rostral or caudal portions of the VTA. It is also conceivable that topographically localized alterations in the function of VTA AMPA receptors fundamentally affect the actions of morphine in other, distal brain regions (e.g., the NAcc; Olds, 1982).

Finally, it is possible that the dopaminergic cells of the caudal VTA are more sensitive to the excitatory (Gysling and Wang, 1983) effects of opiates, and that viral-mediated overexpression of GluR1 renders affected neurons particularly susceptible to depolarization blockade because of consequent increases in sensitivity to glutamate. Depolarization blockade of VTA dopaminergic neurons would be expected to decrease DA release in the NAcc, a condition that could be associated with diminished reward or aversion (see Rompré and Wise, 1989). This possibility is not easily addressed pharmacologically in rats given intra-VTA mi- 

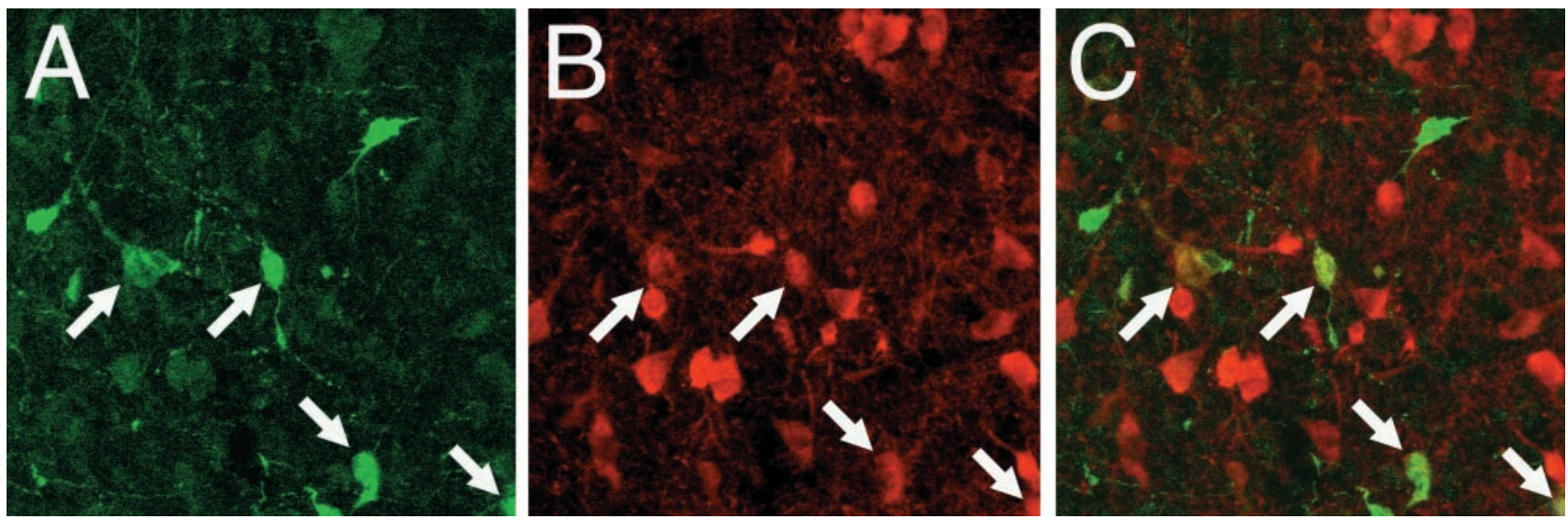

Figure 3. Confocal microscopy (magnification, $400 \times$ ) in a representative slice from the rostral VTA ( $\sim .9 \mathrm{~mm}$ posterior to bregma). $A$, Cells expressing the GluR1-GFP fusion protein are represented by green (FITC) fluorescence. $B$, Cells expressing TH are represented by red (rhodamine) fluorescence. $C$, Overlay of $A$ and $B$, revealing that four of the eight brightly labeled GluR1-GFP cells $(50 \%)$ are dual-labeled, represented by yellow fluorescence. Arrows indicate co-labeled cells.

croinjections of viral vectors, however, because opiates also have direct rewarding actions at opioid receptors in the NAcc (Olds, 1982) that may make studies in which the test dose of morphine is altered difficult to interpret. Rather, this possibility will be addressed in future studies by examining the electrophysiological properties of GluR1-overexpressing neurons isolated from the rostral or caudal VTA, identified visually with the GluR1-GFP fusion protein (Shi et al., 1999). Regardless, the present studies demonstrate the utility of viral-mediated gene transfer for studying the anatomical substrates of drug action and have revealed within the VTA topographically separable motivational effects of opiates.

\section{REFERENCES}

Bozarth MA (1987) Neuroanatomical boundaries of the reward-relevant opiate-receptor field in the ventral tegmental area as mapped by the conditioned place preference method in rats. Brain Res 414:77-84.

Bozarth MA, Wise RA (1981) Intracranial self-administration of morphine into the ventral tegmental area in rats. Life Sci 28:551-555.

Broekkamp CLE, Van den Bogaard JH, Heijnen HJ, Rops RH, Cools AR, Van Rossum JM (1976) Separation of inhibiting and stimulating effects of morphine on self-stimulation behavior by intracerebral microinjections. Eur J Pharmacol 36:443-446.

Brog JS, Salyapongse A, Deutch AY, Zahm DS (1993) The patterns of afferent innervation of the core and shell in the "accumbens" part of the ventral striatum: immunohistochemical detection of retrogradely transported fluoro-gold. J Comp Neurol 338:255-278.

Carlezon Jr WA, Wise RA (1993) Morphine-induced potentiation of brain stimulation reward is enhanced by MK-801. Brain Res 620:339-342.

Carlezon Jr WA, Wise RA (1996) Rewarding actions of phencyclidine and related drugs in nucleus accumbens shell and frontal cortex. J Neurosci 16:3112-3122.

Carlezon Jr WA, Boundy VA, Haile CN, Lane SB, Kalb RG, Neve RL, Nestler EJ (1997) Sensitization to morphine induced by viralmediated gene transfer. Science 277:812-814.

Cornwall J, Cooper JD, Phillipson OT (1990) Afferent and efferent connections of the laterodorsal tegmental nucleus in the rat. Brain Res Bull 25:271-284.

Dahlstrom A, Fuxe K (1964) Evidence for the existence of monoaminecontaining neurons in the central nervous system. Acta Physiol Scand 62[Suppl232]:1-55.

Fitzgerald LW, Ortiz J, Hamedani AG, Nestler EJ (1996) Drugs of abuse and stress increase the expression of GluR1 and NMDAR1 glutamate receptor subunits in the rat ventral tegmental area: common adaptations among cross-sensitizing agents. J Neurosci 16:274-282.

Gysling K, Wang RY (1983) Morphine-induced activation of A10 dopamine neurons in the rat. Brain Res 277:119-127.

Ikemoto S, Kohl RR, McBride WJ (1997a) GABA A receptor blockade in the anterior ventral tegmental area increases extracellular levels of dopamine in the nucleus accumbens of rats. J Neurochem 69:137-143. Ikemoto S, Murphy JM, McBride WJ (1997b) Self-infusion of GABA antagonists directly into the ventral tegmental area and adjacent areas. Behav Neurosci 111:369-380.

Johnson SW, North RA (1992) Opioids excite dopamine neurons by hyperpolarization of local interneurons. J Neurosci 12:483-488.

Koob GF, Nestler EJ (1997) The neurobiology of drug addiction. J Neuropsychiatry Clin Neurosci 9:482-497.

Leone P, Pocock D, Wise RA (1991) Morphine-dopamine interaction: ventral tegmental morphine increases nucleus accumbens dopamine release. Pharmacol Biochem Behav 39:469-472.

Neve RL, Howe JR, Hong S, Kalb RG (1997) Introduction of the glutamate receptor subunit 1 into motor neurons in vitro and in vivo using a recombinant herpes simplex virus. Neuroscience 79:435-445.

Olds ME (1982) Reinforcing effects of morphine in the nucleus accumbens. Brain Res 237:429-440.

Olmstead MC, Munn EM, Franklin KBJ, Wise RA (1998) Effects of pedunculopontine tegmental nucleus lesions on responding for intravenous heroin under different schedules of reinforcement. J Neurosci 18:5035-5044.

Paxinos G, Watson C (1986) The rat brain in stereotaxic coordinates, Ed 2. San Diego: Academic.

Rompré P-P, Wise RA (1989) Opioid-neuroleptic interaction in brain stem self-stimulation. Brain Res 477:144-151.

Rossi NA, Reid LD (1976) Affective states associated with morphine injections. Physiol Psychol 4:269-274.

Shi SH, Hayashi Y, Petralia RS, Zaman SH, Wenthold RJ, Svoboda K, Malinow R (1999) Rapid spine delivery and redistribution of AMPA receptors after synaptic NMDA receptor activation. Science 284:1811-1816.

Stewart J (1984) Reinstatement of heroin and cocaine selfadministration behavior in the rat by intracerebral application of morphine in the ventral tegmental area. Pharmacol Biochem Behav 20:917-923

Swanson LW (1982) The projections of the ventral tegmental area and adjacent regions: a combined fluorescent retrograde tracer and immunofluorescence study in the rat. Brain Res Bull 9:321-353.

Walaas I, Fonnum F (1980) Biochemical evidence for $\gamma$-aminobutyrate containing fibres from the nucleus accumbens to the substantia nigra and ventral tegmental area in the rat. Neuroscience 5:63-72.

Weeks JR, Collins RJ (1964) Factors affecting voluntary morphine intake in self-maintained addicted rats. Psychopharmacology 6:267-279.

Wise RA (1998) Drug-activation of brain reward pathways. Drug Alcohol Depend 51:13-22.

Zhang Z-F, Hu X-T, White FJ, Wolf ME (1997) Increased responsiveness of ventral tegmental area dopamine neurons to glutamate after repeated admininstration of cocaine or amphetamine is transient and selectively involves AMPA receptors. J Pharmacol Exp Ther 281:699-706. 